\title{
Application of Specific Theory of Constraints Technique for the Identification of Main Causes of Negative Consequences within Procurement Logistics
}

\author{
Larisa M. Kapustina $^{1}$, Mária Chovancová ${ }^{2 *}$ and Vladimír Klapita ${ }^{2}$ \\ ${ }^{1}$ Ural State University of Economics, 8 Marta, 62, 620144, Yekaterinburg, Russia; Email: \\ lakapustina@bk.ru \\ ${ }^{2}$ University of Žilina, Department of Railway Transport, Univerzitná 1, 010 26, Žilina, Slovak \\ Republic; Email: maria.chovancova@fpedas.uniza.sk
}

\section{*Corresponding Author: Mária Chovancová}

\begin{abstract}
The paper presents a concrete example of the selected Theory of Constraints (TOC) technique implementation in order to identify the main causes of undesirable consequences in the context of supply logistics issues. Determining the undesirable consequences of supply logistics is primarily related to the adverse impact on costs, profitability and quality of outsourcing enterprise which provide services in supply chain field. Particularly, this implementation includes individual steps of the process related to the creation of the specific TOC technique. The outcome is to identify the main causes which have the most significant impact on the negative consequences.
\end{abstract}

Keywords: Theory of Constraints, procurement logistic, supply chain, outsourcing, main causes, negative consequences

\section{Introduction}

Procurement logistics is a comprehensive process of integrating several subsystems regarding purchase or procurement processes among which numerous relationships occur. The subsystems are affected by each other and this may have positive as well as negative effects on them ultimately.

Therefore, it is necessary to address the optimization of individual production processes within the supply chain. Understanding of current function state and interrelationship of the various elements in the system is the basis for such an optimization.

There are various methods utilized to present the current state and its links in the procurement logistics. Current Reality Tree known as CRT diagram belongs among them. It allows for identification of negative impacts and understanding main causes in the whole system. CRT diagram is a method of "Thinking processes" within the Theory of constraints which is used to analyze the adverse effects and identification of causes. 


\section{The process of creating the TOC technique}

Construction of the CRT diagram consists of several subsequent steps. Firstly, it is necessary to determine the range of analysis in order to reveal the main causes. If the selected part of the procurement logistics is too small, the main causes will not be detected usually. On the contrary, if the selected part of the system is too large, the quality of final results will be decreased $[1,2]$.

Borders of the CRT diagram are represented by suppliers and customers of the production enterprise. Each enterprise creates certain amount of inventory in order to ensure the continuity of procurement process and adequate customer service. There is a need to take into account the impact of inventory level on the increase in costs. Thus, the purpose of the CRT diagram is to identify the elements of the procurement logistics, as a part of the supply chain, that have the most significant impact on the mentioned costs of the enterprise as well as the customer service level [3-5].

\section{Identification of the most important issues}

The basis for construction of the CRT diagram is to define particular subjects, i.e. negative consequences, which limit and restrict the procurement logistics functionality. In general, abbreviation "UDE" is common for these subjects. Within the examined part of the supply chain, there are three basic subjects [6,7]:

- suppliers,

- procurement enterprise (outsourcer),

- customers.

The supplier affects the procurement process of the supply chain by its ability to deliver the required material at the exact time period, on the right place and in the required quality. These attributes have effects especially on the procurement continuity in enterprise and on provided customer service level. The risk of inventory deficiency is increased due to the unreliability of suppliers. It can be the reason for disruption of the procurement continuity, customer service level reduction and costs increase [6,8-10].

In case that the minimum amount of one delivery is determined, inventory level in the warehouse and the resulting costs will increase. Otherwise, if the determined amount of one delivery is not fulfilled, unit delivery costs will increase [7,8].

Inventory warehousing and inventory maintenance costs increase proportionally with the inventory level increase in the enterprise as well as inventory fixes more capital of enterprise. The increase of capital bound in inventory is also caused due to long delivery times. It results from the need of holding the higher inventory level in the enterprise. The higher inventory level also means a higher risk of unused inventory which also causes generating certain costs [8-10]. 
Continual procurement process of the supply chain is also significantly affected by unexpected changes in the consumption intensity which is caused by fluctuations in customer requirements and fluctuations in consumption resulting from a nature of procurement $[6-8,10]$.

On the basis of above mentioned, issues, which are able to affect significantly the smooth functionality of the supply chain process, are identified (see Table 1).

Table 1 Subjects restricting the function of the production processes. Source: [authors]

\begin{tabular}{ll}
\hline UDE & Mark \\
\hline Breach of delivery time & $\mathrm{A}$ \\
\hline Incorrect delivery amount & $\mathrm{B}$ \\
\hline Insufficient delivery quality & $\mathrm{C}$ \\
\hline Risk of inventory deficiency & $\mathrm{D}$ \\
\hline Costs resulting from the inventory deficiency & $\mathrm{E}$ \\
\hline Disruption in procurement & $\mathrm{F}$ \\
\hline Reducing customer service level & $\mathrm{G}$ \\
\hline Delivery amount higher than the consumption & $\mathrm{H}$ \\
\hline High delivery costs & $\mathrm{I}$ \\
\hline Low delivery flexibility & $\mathrm{J}$ \\
\hline High inventory level in the warehouse & $\mathrm{K}$ \\
\hline High costs for inventory storage and maintenance & $\mathrm{L}$ \\
\hline High capital bound & $\mathrm{M}$ \\
\hline Long delivery time & $\mathrm{N}$ \\
\hline Risk of unused inventory & $\mathrm{O}$ \\
\hline Costs arising from unused inventory & $\mathrm{P}$ \\
\hline Unexpected changes of consumption intensity & $\mathrm{Q}$ \\
\hline Fluctuations in customer requirements & $\mathrm{R}$ \\
\hline Fluctuations in consumption & $\mathrm{S}$ \\
\hline
\end{tabular}

From the list, it is necessary to select 5-10 of the most important issues (relevant subjects). Subsequently, the causal relationships must be created between relevant subjects. These subjects are the basis for the diagram construction and other specified problems will be used later. The relevant subjects are summarized in previous Table 1, indicated by gray color. 


\section{Particular TOC diagram}

When creating the CRT diagram, subsequent steps must proceed from top to bottom. As for the first step, two subjects, between which a relationship of cause and effect is present, are selected. CRT diagram is gradually extended by relevant subjects in order to help to understand what links are between negative consequences and what combinations have consequences $[12,13]$.

Then, CRT diagram needs to be read from bottom to resulting undesirable effect by the formulation "if ...then...". In Figure 1, the relevant subjects by blue are shown and other subjects, which were subsequently added to the CRT diagram, are identified by black.

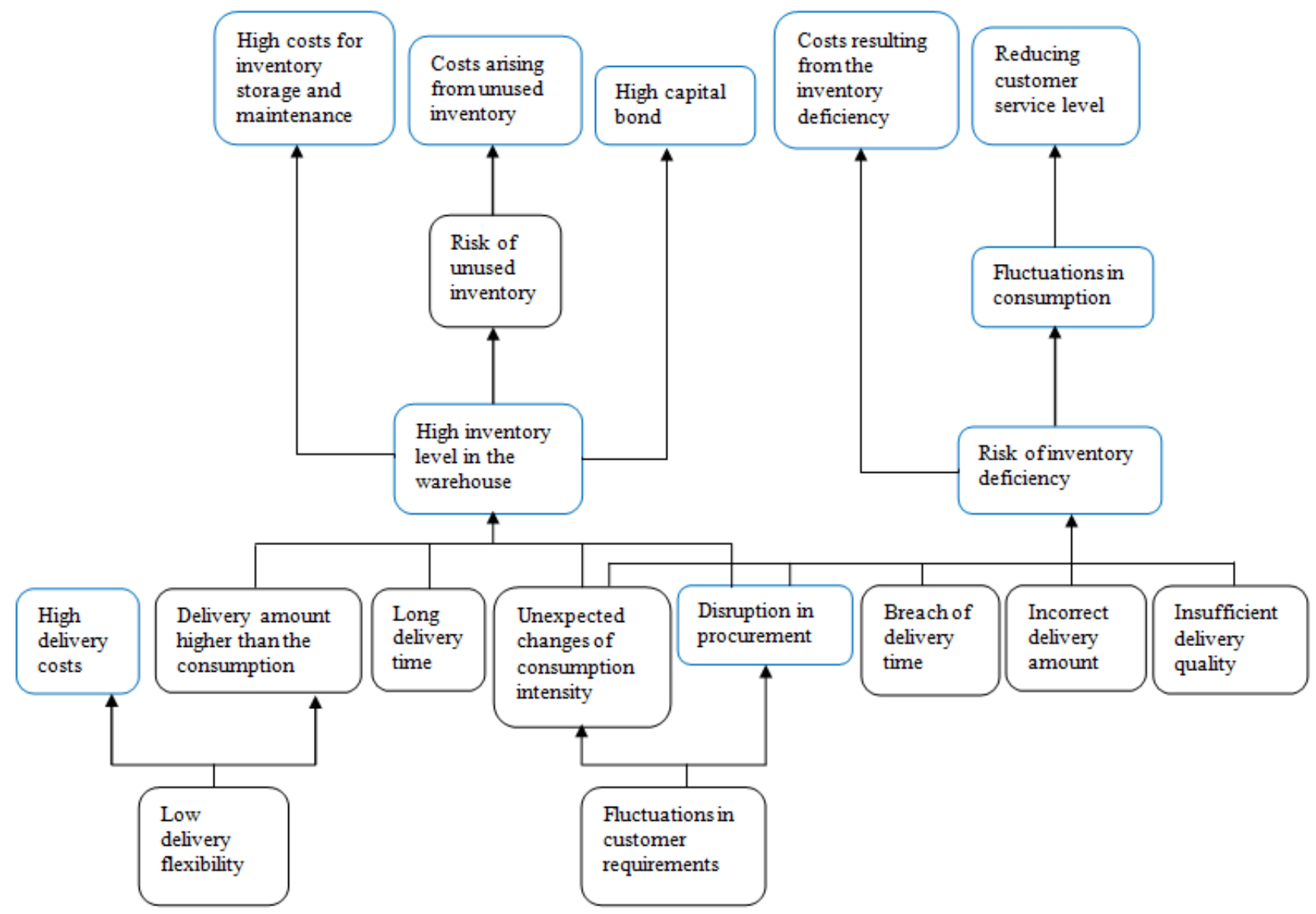

Fig. 1 Construction of the specific TOC technique regarding procurement processes. Source: [authors]

\section{Determination of the main causes}

As for the first step in regard to system constraints determination, there is a need to specify those subjects which need to be removed from the system. These subjects are undesirable itself in the system. There are indicated by yellow (see Figure 2) 


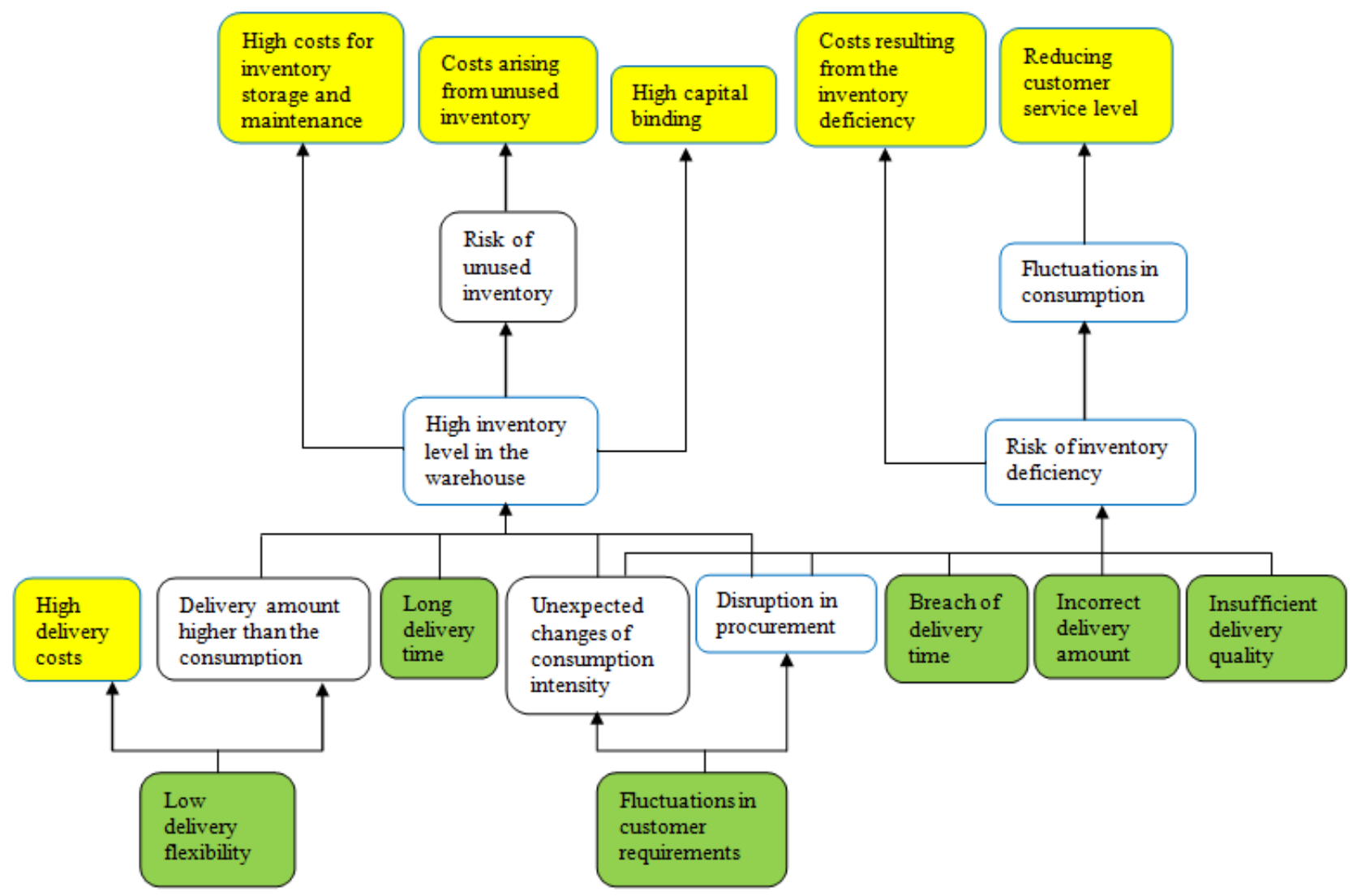

Fig. 2 Resulting TOC technique in terms of procurement processes. Source: [authors]

Selected subjects are used to build a table. Based on the table, main causes (system constraints $=$ the most significant deficiencies) are identified. In the top line of Table 2, subjects indicated by yellow in the previous TOC technique are summarized. In the left column, entry subjects (in the diagram, they are indicated by green) are shown. Table 2 shows the effect of entry subjects on relevant subjects as follows[12-14]:

- if the entry entity causes some of the relevant subjects, value 1 is inserted in the table then,

- if the entry entity does not cause some of the relevant subjects, value 0 is inserted in the table.

Such entity, which reaches more than $80 \%$, is considered the key entity. 
Table 2 Impact of entry subjects on relevant subjects in terms of production processes. Source: [authors]

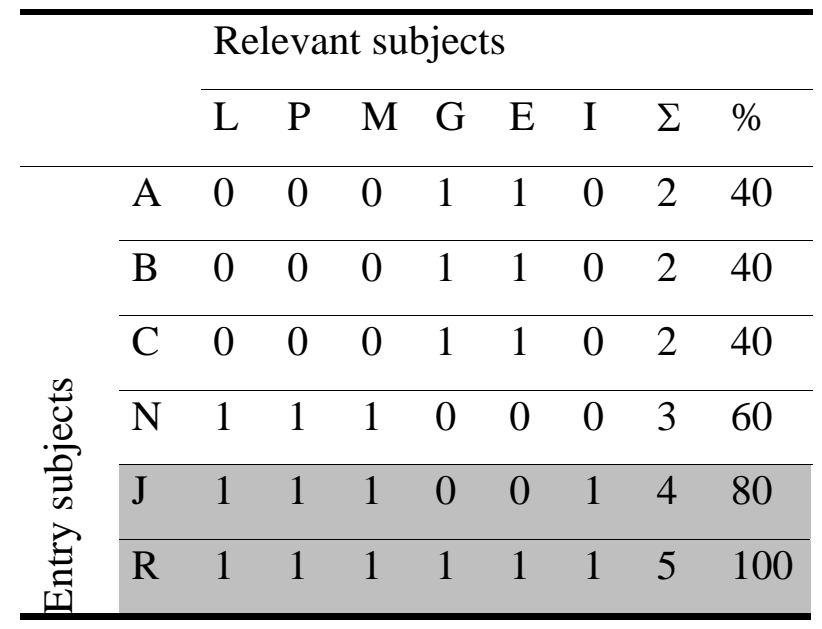

The Table 2 shows that low delivery deficiency and fluctuations in customer requirements have the most significant impact on the functional procurement processes. For this reason, it is necessary that the enterprise also puts emphasis on demand forecasting, in particular when considering the variability over time. And also, given the fact that everything depends on changing customer demand, flexible deliveries are a great benefit to operation of the whole procurement logistics [13].

\section{Conclusion}

The objective of the paper was to identify subjects and relationships within procurement processes which have an adverse impact on enterprise costs and customer service level. The aim was achieved by creating the specific TOC technique. Based on an analysis of the particular procurement processes and activities in the specific enterprise using TOC diagram, it was found that two factors (negative consequences) have the most significant impact on this enterprise costs and the customer service level.

As for the first one, fluctuations in customer requirements were specified. The bigger fluctuation is, the higher need for inventory holding in the warehouse is, and outcome consists in increased costs. In case of insufficient inventory level in the enterprise, the continuity of procurement logistics is disrupted. Ultimately, it results in the decreasing customer service level.

The second factor, which significantly influences the procurement processes functionality, is related to the flexible deliveries, i.e. suppliers delivering material into the enterprise processes. If the delivery amount is explicitly determined, e.g. truck or loading unit capacity, the inventory level in the warehouse is expanded and this results in increased operating costs. 


\section{Acknowledgments}

The paper is supported by the VEGA Agency by the Project 1/0095/16 "Assessment of the quality of connections on the transport network as a tool to enhance the competitiveness of public passenger transport system", that is solved at Faculty of Operations and Economics of Transport and Communication, University of Žilina.

\section{References}

[1] Chaudhari, C.V. \& Mukhopadhyay, S.K. (2003). Application of theory of constraints in an integrated poultry industry. International Journal of Production Research, 41 (4), 799-817. DOI: $10.1080 / 0020754031000065548$.

[2] Wee, H.M., Budiman, S.D., Su, L.C., Chang, M. \& Chen, R. (2016). Responsible supply chain management - an analysis of Taiwanese gutter oil scandal using the theory of constraint. International journal of logistics-research and applications, 19 (5), 380-394. DOI: 10.1080/13675567.2015.1090964.

[3] Simatupang, T.M., Wright, A.C. \& Sridharan, R. (2004). Applying the theory of constraints to supply chain collaboration. Supply chain management-an international journal, 9 (1), 57-70. DOI: $10.1108 / 13598540410517584$.

[4] Puche, J., Ponte, B., Costas, J., Pino, R. \& de la Fuente, D. (2016). Systemic approach to supply chain management through the viable system model and the theory of constraints. Production planning \& control, 27 (5), 421-430 DOI: 10.1080/09537287.2015.1132349.

[5] Simatupang, TM., Wright, AC. \& Sridharan, R. (2004). Applying the theory of constraints to supply chain collaboration. Supply Chain Management: An International Journal, 9 (1), 57-70. DOI: $10.1108 / 13598540410517584$.

[6] Chen, L. Yucel, S. \& Zhu, K.J. (2017). Inventory management in a closedloop supply chain with advance demand information. Operations research letters, 45 (2), 175 180. DOI: $10.1016 /$ j.orl.2017.02.002.

[7] Bertazzi, L., Bosco, A. \& Lagana, D. (2016). Min-Max exact and heuristic policies for a twoechelon supply chain with inventory and transportation procurement decisions. Transportation research part e-logistics and transportation review, 93, 57-70. DOI: 10.1016/j.tre.2016.05.008.

[8] Li, J.C., Zhou, Y.W. \& Huang, W.Y. (2017). Production and procurement strategies for seasonal product supply chain under yield uncertainty with commitment-option contracts. 
International journal of production economics, 183, 208-222. Part: A. DOI: $10.1016 /$ j.ijpe.2016.10.019

[9] Sarkar, S. \& Kumar, S. (2015). A behavioral experiment on inventory management with supply chain disruption. International journal of production economics, 169, 169-178. DOI: 10.1016/j.ijpe.2015.07.032.

[10] Chen, K.B., Shen, J.L. \& Feng, M.L. (2014). Disruptions management of a supply chain under strategic subsidy policy for the demand-stimulating inventory. Computers \& industrial engineering, 76, 169-182. DOI: 10.1016/j.cie.2014.07.030

[11] Selviaridis, K. (2014). Building Lean Supply Chains with the Theory of Constraints. Journal of purchasing and supply management, 20 (4), 286-287. DOI: 10.1016/j.pursup.2014.09.001.

[12] Tsou, C.M. (2013). On the strategy of supply chain collaboration based on dynamic inventory target level management: A theory of constraint perspective. Applied mathematical modeling, 37 (7), 5204-5214. DOI: 10.1016/j.apm.2012.10.031.

[13] Kirche, E.T., Kadipasaoglu, S.N. \& Khumawala, B.M. (2005). Maximizing supply chain profits with effective order management: integration of Activity-Based Costing and Theory of Constraints with mixed-integer modeling. International journal of production research, 43 (7), 1297-1311. DOI: 10.1080/00207540412331299648

[14] Oglethorpe, D. \& Heron, G. (2013). Testing the theory of constraints in UK local food supply chains. International journal of operations \& production management, 33 (10), 1346-1367. DOI: 10.1108/IJOPM-05-2011-0192. 